\title{
Conservation and vulnerability analysis of architectural heritage on small islands: a case study of Kinmen
}

\author{
Y. J. Tseng \\ Department of Architecture, National Quemoy University, Taiwan
}

\begin{abstract}
The military control throughout the nearly half-century cross-strait stand-off during the Cold War since 1949 has left Kinmen with a large number of unintentionally preserved traditional Minnan (Southern Fujian) buildings and villages along with an extensive group of military buildings, battlefield infrastructure at this forefront against communist invasion. The island has a rich architectural heritage. However, substantive changes took place after the termination of military administration in 1992 and the commencement of Mini Three Links in 2001. Kinmen's conservation of traditional architecture has thereafter been exposed to the impact of cheap materials and architectural styles from the Chinese Mainland. One consequent change is that the traditional construction industry is now relying more on the fast and cheap customized production than local craftsmanship. The local craftsmen are fading from the scene as it is difficult for them to adapt to new work process and find apprentices to transfer the know-how. The current situation in the industry is affecting the development of traditional architecture conservation, bringing out issues such as outdated conservation ideas, endangered traditional craftsmanship and insufficient resources. The change in architectural thinking underlines the vulnerable nature of traditional architecture conservation and cultural resilience. This paper studies the vulnerability of the local architectural heritage in the context of the particular background of Kinmen Island under the impact from the dominant Mainland Chinese economics and culture.

Keywords: military administration, traditional architecture, mini three links, traditional craftsmen.
\end{abstract}




\section{Introduction}

Kinmen, located $10 \mathrm{~km}$ from Xiamen City, southern Fujian (Minnan), China, is the largest outlying island of Taiwan. The agricultural immigration in Kinmen, mainly from neighbouring Chinese cities such as Quanzhou and Zhangzhou, was documented as early as the ninth-century during the Tang Dynasty. With the fortifications constructed against pirates during the Ming Dynasty in the fourteenth century, the strategically located Kinmen became an important defensive island in the southern Fujian, safeguarding the coastal and maritime safety. In the middle of nineteenth century, the lifting of the ban on Chinese nationals travelling to other countries for business and work turned Kinmen into a springboard that spread Chinese culture to other areas while opening its arms to other cultures. As a result, on the basis of the attributes of its native Minnan culture, the island embraced an eclectic fusion of Minnan and Western styles in the late nineteenth century. In 1949, the two sides of the Chinese Civil War, the Nationalists and the Communists, confronted here and caused the well-known "Quemoy Crisis" of the Cold War [1]. The role of Kinmen changed then from the first defence against external forces from thirteenth to nineteenth century to the front line of the US-led containment of Communism [2]. The island also became a test field for defence and new administration.

Due to the mentioned geographical characteristics and historical background, Kinmen has preserved its specific environment as an island and a largest number of villages, traditional buildings and overseas funded western-style buildings during the 43 years under military rule. It consists of an extraordinary cultural heritage even in Taiwan and in the Chinese Minnan region. Substantive changes in traditional architectural and cultural system took place after the demilitarisation in 1992 and the reopening of cross-strait contacts in 2001. After Kinmen restored the contact with the construction industry of its native towns, the geographical proximity and the convenient transport has led to the import of cheap materials and even craftsmen from the Chinese Mainland.

Architecture is a human product specific to the natural and social environment, and the construction of traditional architecture usually follows certain plans and programs that reflect local cultural rules and social order. Through harmonious cooperation between the property owner and the craftsmen who share the same values, a traditional building is created to fulfil physical and spiritual needs in accordance to collective consciousness and social constraints of a traditional society. Traditional building techniques are thus carried forward in this kind of construction operation co-directed by the property owner and traditional builders. However, the traditional architecture conservation in Kinmen today is impacted by modern construction industry while the style is influenced increasingly by the cheap materials from China. As a result, the local construction industry has developed a very different mode of operation, form and decorative aesthetics of traditional architecture are slowly changing. This paper studies the dilemma and development in preserving traditional architecture and craftsmanship in Kinmen in relation to its particular background, highlighting the vulnerability of local cultural heritage under current impacts from China. 


\section{Historical background}

Located opposite Xiamen Island, China, between Jiulong River Estuary and Weitou Bay, Kinmen is close to Quanzhou and Zhangzhou and other areas in southern Fujian where lie the roots of most people in Kinmen. Kinmen is an island short of resources. Apart from the locally produced stone and stucco, all other materials required for local house construction, such as granite, limestone, other finer stones, bricks, tiles and timbers, had to be imported from Quanzhou, Zhangzhou and other areas. Master carpenters, masons and other traditional craftsmen were also hired from the same areas for construction projects in Kinmen. Additionally, due to geographical proximity and shared ancestors, the traditional buildings in Kinmen simply copied the layout and forms of those in their native towns, with the crafts featuring the characteristics of their native culture. However, the development of this island's architecture is similar to that of its culture, which incorporated local wisdom and overseas influence into the basis of the immigrants' native culture during hundreds of years.

In 1860, Chinese government was forced by imperialism to allow people to work abroad. Many residents of the resource-deprived Kinmen Island went overseas to make a living, contributing to an economic and cultural integration from other countries in Kinmen. Some of the emigrants became wealthy businessmen and returned home to build grandiose mansions and ancestral halls. The overseas remittances drove several construction waves, including the traditional houses springing up in the late nineteenth century, such as the Chongbao group of buildings in Shanghou (Fig. 1) which were built with remittance from Japan during 1876-1900. Later, the influx of other cultures led to the emergence of western-style houses in the early twentieth century, such as Zhen Shi-Yin Western-Style House (Fig. 2). These Western-style buildings were influenced by Western colonial style, embracing contemporary exotic elements on the basis of traditional construction concepts.

From 1949, the cross-strait exchanges of goods and personnel were interrupted by the military stand-off during the Cold War. For military

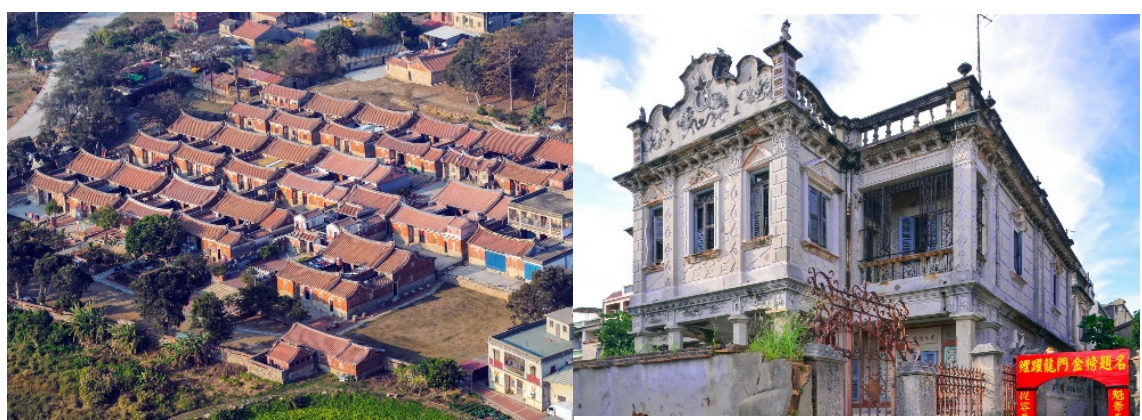

Figure 1: Chongbao group of Figure 2: Zhen Shi-Yin Westernbuildings in Shanghou. Style House. 
construction use, cement hollow bricks and roof tiles were produced by the defence and reinforced concrete was extensively used to build fortifications. The established supply of Mainland materials and craftsmen for local civilian buildings was suddenly out of reach yet it was impossible to import required materials from the main island of Taiwan either. Therefore, in the beginning, damaged civilian buildings were repaired with locally produced materials, used materials and cement, bricks and roof tiles produced by the army. Today, those roofs and walls repaired with cement tilts and hollow bricks in the 1950s remain to be seen commonly on the island. It was not until the 1960s that materials for traditional architecture from the main island of Taiwan became gradually available. Later in the 1980s, when the Communist People's Liberation Army (PLA) ended its shelling campaign, massive conservation started with abundant supply of bricks, tiles and timbers from Taiwan. Nevertheless, it was the fashion in those days to use reinforced concrete structure in place of traditional wooden structure and modern coloured tiles in place of wall decoration. That fashion thus became the features of the traditional architecture of that period.

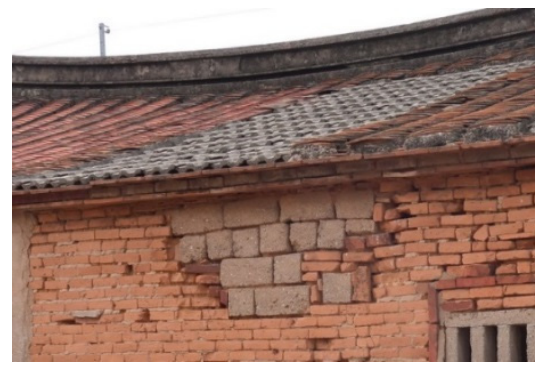

Figure 3: The mixed use of cement tiles and hollow bricks for conservation in the $1950 \mathrm{~s}$.

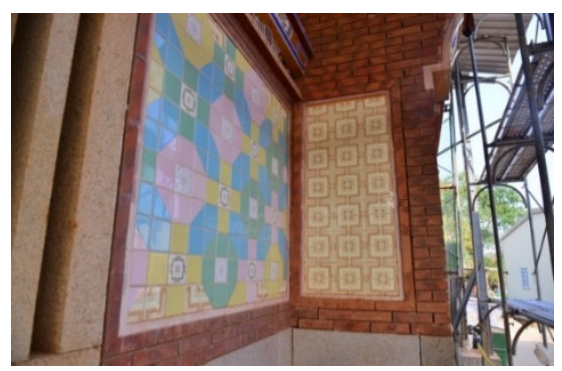

Figure 4: The use of modern coloured tiles for conservation in the 1970s.

In 1992, the island was demilitarised and statistics showed that the gross production of the construction industry in Kinmen that year doubled that of the previous year. The first peak of conservation demand occurred in 1995 when the Kinmen National Park was established. The National Park promoted the preservation of traditional villages and the conservation of traditional buildings by providing incentives for restoring the traditional architecture located within the Park. At this time, bricks, roof tiles and timber imported from Taiwan and new building materials introduced by modern construction companies were used on traditional architecture. For example, stones imported from China via a third place were adopted and stone structure and sculptures were used in place of traditional clay sculptures and tiles on the walls.

With the establishment of the Mini Three Links between Taiwan and China in 2001 and the following liberalization of cross-strait building material trading with special permit, the network between Kinmen and its original towns was 
reconnected after a 50-year separation and their traditional construction and craft industries also regained the contact. As a result of the geographical proximity, convenient marine transport and low cost of Chinese building materials, the majority of the materials required for conservation work in Kinmen have since then been imported from China. Moreover, the construction companies have been outsourcing whole projects to Chinese EPC contractors for stone sculptures and wood structures. The masonry works are designed and produced by Chinese craftsmen and later assembled and maintained by local craftsmen in Kinmen. The special pattern of collaboration formed between the traditional construction industries across the strait is having an impact on the development of techniques and construction culture.

\section{Traditional architecture conservation in incentive scheme}

Although the military administration of almost half century preserved accidentally a large group of traditional buildings, the damages caused by conflicts and the massive evacuation of refugees to the main island of Taiwan left Kinmen with many old houses abandoned or ruined. To protect this architectural heritage was actually one of the objectives of the establishment of the Kinmen National Park in 1995. In accordance to the "Practices of Incentives and Subsidies for Traditional Architectural Style Conservation", the Park started to grant subsidies for conservation of traditional buildings located in the park in 1999. Soon the Kinmen County Government also started to provide conservation rewards in 2001 to encourage the residents to participate in the preservation and conservation of the traditional architecture and rural-urban landscape. The subsidy programs of these two institutes aim to, on one hand, encourage the local residents to involve in the conservation and value their own architectural heritage and, on the other hand, to motivate them to initiate the conservation by providing incentives for preserving the landscape of settlements and protecting the traditional architecture. In this scheme, each building restored is eligible to up to $50 \%$ of the total conservation cost while the subsidy may not exceed NT\$ 2 million. Since then, with forty to fifty buildings restored with such funding each year, more than 750 traditional buildings have been conserved, accounting for more than one quarter of the traditional architecture in Kinmen.

An old saying about renovation of traditional buildings goes "a small renovation every 30 years and a major one every 50 years", reflecting the need to renovate worn and tired structures and materials in the life cycle of a building. Through renovation, the property owner will incorporate contemporary facilities and equipment required while repairing the building to ensure security so that the user may enjoy living in the building and the building may prolong the life. Additionally, traditional craftsmen will have the opportunity to work and pass down the techniques through renovation projects. Therefore, to restore a traditional building is not only to conserve a tangible architectural heritage but to preserve a key venue of the intangible craftsmanship. After the rapid development in the 1980s, Kinmen is now the only place left with a large group 
of traditional buildings and also the county with the bigger traditional building craft industry and the largest number professional building craftsmen in Taiwan.

Prior to 2001, due to the lack of material under military rule, the result of the architecture conservation reflects the traditional architectural heritage. Out of the total of 46 ancestral halls renovated between 1980 and 1992, for example, only two buildings were restored to its original design or with minor changes, ten were partially renovated with new structures, and the rest of some thirty four went through major refurbishment [3]. In those buildings, the original wooden structures were replaced by reinforced concrete structures, while the master carpenters still followed the traditional scales and techniques. In other words, although wood was replaced with reinforce concrete in the structures, the rest of the structure was still made with traditional method and materials. In the closed system of Kinmen, constant conservation projects sustained the traditional craftsmanship and preserved such a heritage, and a renovated building usually retained its traditional rustic atmosphere.

After building materials are allowed to be imported from China via the Mini Three Links in 2001, a large number of stone sculptures, wood structures, bricks and roof tiles have been introduced to renovate ancestral halls in Kinmen. The walls, wooden structures, clay sculptures and decorative paintings made or renewed before 1949 of many ancestral halls were discarded altogether. Likewise, the RC-made imitation wood structure installed in renovation between 1970 and the 1990s were replaced again with customized Chinese-made traditional wooden structure. The original brick or stone walls decorated with coloured tiles were replaced with new brick walls on reinforced cement bases with thick and strong limestone high-relief, while the traditional wooden pillars were replaced with polished stone pillars. As to the residential house renovation, many property owners regarded the original walls, constructions and decorative elements as outdated practices in times of economic difficulties. They also considered the traditional "wrap-around" brick walls or adobe walls not safe enough. In place of original walls, they opted for thus walls of modern machinemade bricks on RC bases and covered the walls with bricks decorated with grey and black strips to imitate the "smoked bricks" to create a "traditional" appearance.

The incentive schemes aim to promote conservation in order to conserve the buildings and preserve the settlement. However, in the restored ancestral halls, the stone carvings were often badly done and stones were broadly used as material yet seem overly modern and show no artistic. As a result, the gentle and light touch in their original traditional crafts and ornaments has been dramatically changed. In the cases of restored houses, most of the original materials were disposed while modern red bricks and cement were extensively applied. Moreover, the artificial stripes that imitate the natural pattern on traditional bricks make the restored walls appear dull, losing their original natural and simple style. It is likely because, on the one hand, the property owners thought that the value of renovation lies in making the buildings brand new again. Therefore they believed they had to change the materials, rebuild the walls and replace the bricks and roof tiles to make a renovation meaningful. On 
the other hand, the government only requires the buildings that receive conservation subsidies to feature traditional forms and style. There is no effective controls on whether the structure of a wall can be replaced or how the original bricks and roof tiles should be preserved and kept. The relatively limited subsidies control in fact the "style" only, that is, as long as there are not too many major changes to the appearance and the decoration materials and structures are "in a traditional form".

Such development shows that, without an appropriate approach to preservation and awareness of the importance of authenticity and integrity, even a goodwill government subsidy scheme may result in a massive disposal of original objects by an architectural heritage conservation project. Additionally, cheap, fast and convenient building materials from China are prevailing in the traditional architectural industry in Kinmen.

\section{Vulnerability of architectural heritage: development under changed construction thinking}

Renovation of traditional architecture implies the inheritance of rules and orders. Through the implementation of traditional knowledge and techniques, a traditional building will be reincarnated to achieve the purpose of carrying out traditional values into the future. The conservation of traditional buildings, often due to damages, involves a complex social background and professional construction model. Since the reopening of cross-strait contacts in 2001, the new system and cultural thoughts are evidently reflected on the restored buildings. One of the resulting changes is that the traditional construction industry is now relying on the fast and economical supply of customized products from China instead of local craftsmen. As a result, traditional craftsmen have difficulties in carrying on working in such a different situation and finding someone to succeed them. The current construction practices have thus an impact on the form and the development of the restored traditional architecture. The consequent changes in the appearance and cultural relevance of traditional architecture highlight issues such as the professional craft skills in danger and the vulnerability of traditional architecture preservation.

The concept of vulnerability is mainly applied to hazard and disaster issues, but can also be applied to the relation between people and their living environment as well as socio-economic situation, including social forces, cultural values, political and ecological impact. Therefore, vulnerability should involve a predictive quality: It is supposedly a way of conceptualizing what may happen to an identifiable population under conditions of particular risks and hazards [4]. Vulnerability is registered not by exposure to hazards (perturbations and stresses) alone but also resides in the sensitivity and resilience of the system experiencing such hazards [5]. The vulnerability of a system, population or individual to a threat relates to its capacity to be harmed by that threat [6].

The vulnerability of the architectural heritage of Kinmen is mainly reflected in the changes in structure and ornamentation system under the impact of the reconnection between the construction industries across the strait. Without 
the awareness of the importance of authenticity, to renew and replace instead of preserving the original objects became the direction of development. The pursuit of new materials and structures indicates the disrespect of the materials of historic and cultural values. It is not only harmful to the architectural heritage entity. In addition, in the face of dominant new construction culture of China, the transfer of crafts skills is also jeopardised, as the current administration has failed to put forward appropriate response mechanism to assist the inheritance and protection.

\subsection{Changes in structure and ornamentation system}

From 2001, building materials are allowed to be imported from China on application basis. The direct introduction of ornament materials for traditional architecture reflects a trend in the free market economy. Kinmen is conveniently close to China where affordable materials are available for selection and purchase. In addition, convinced that traditional adobe or brick structures are of low quality and not safe enough, local residents think those should be replaced with modern machine-made bricks or strengthened with RC columns and beams. Local residents also think that the ornaments on facade, such as clay sculptures, coloured tiles or rustic plain wall bases made of slate do not mirror their financial capabilities. For them, stone is a durable material. As a result, the simple amicable clay sculptures and decorative paintings featuring characteristics of local craftsmanship are substituted by complex relief sculptures processed with modern machinery. The old-fashioned windows made from carved wood become stone sculpture windows. Furthermore, the laser engraved landscape on stone sculptures completely overturned the characteristics of traditional crafts and style of art. These changes in structures and ornamentation forms reflect the architectural development in a modern fast construction industry. The vulnerability of architectural tradition of a remote island in contact with a dominant culture and economy is made obviously through the mentioned changes brought to the style of local traditional architecture by a conservation trend and even the resulting end to the existing culture and skills.

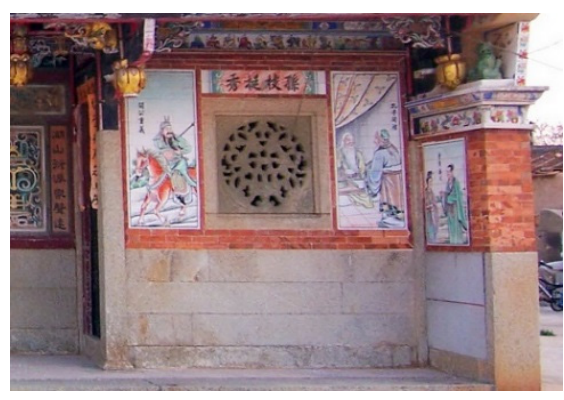

Figure 5: A wall before renovation.

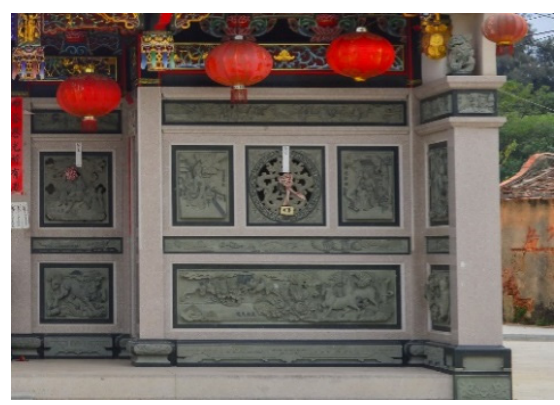

Figure 6: The same wall after renovation. 


\subsection{Property owner's misconceptions about architectural conservation}

In many renovation projects of ancestral halls and houses, some would be aware and want to preserve usable original objects as a symbol of the history and cultural heritage for the historical context of the ancestral halls during centuries or out of the attachment to their own houses. Although some of them are highrank government officials responsible for promoting cultural heritage conservation, they would still find it difficult to persuade the decision-making clan elders or family members. In addition to the traditional lack of architectural and cultural conservation awareness, another cause might be the common viewpoint that a worthy renovation means "to get rid of the old to make way for the new," as a building is only renovated every few decades. It has also been commonly thought that the old structures and materials are outdated and, moreover, the failure to renovate ancestral halls with new materials would bring shame on the ancestors. This is contrary to the prevailing conception in Europe and America that it is an honour to safeguard the cultural heritage left by the ancestors. Therefore, in absence of direct original evidence, the "incomplete" current status would rather be maintained to show the life history of a building and its historic and cultural characteristics. Any excessive renovation,

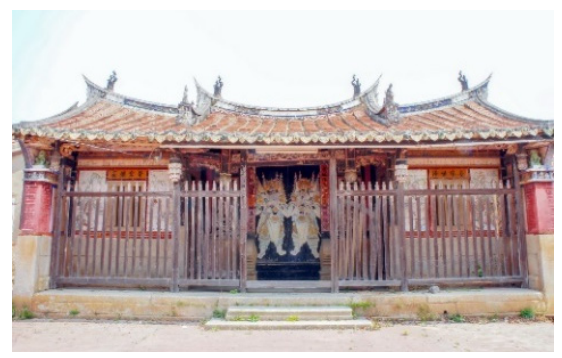

Figure 7: Beishan Ancestral Hall before renovation.

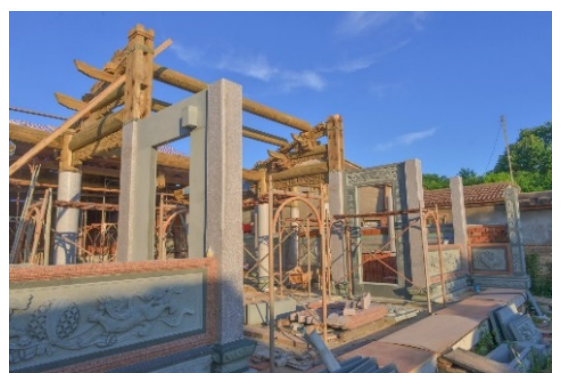

Figure 9: The structure of the ancestral hall is largely renewed.

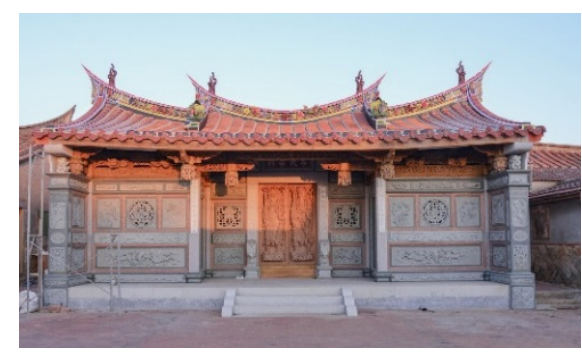

Figure 8: Beishan Ancestral Hall after renovation.

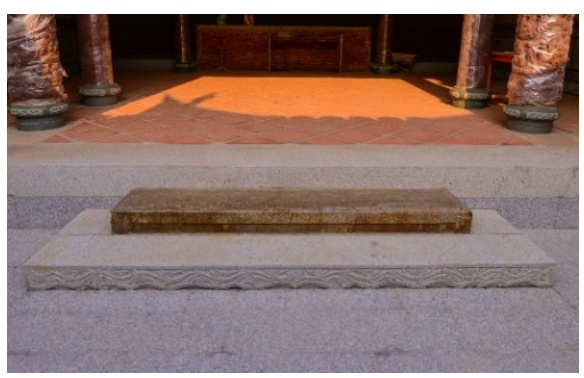

Figure 10: Only a stone step is preserved from the entire original ancestral hall. 
improvement, modification even faking would also be avoided to prevent being lost in fake values.

However, in the traditional Chinese society, it has been believed that renovation means to remove all the old elements that are inconsistent with the contemporary security standards or fashion trend, regardless of their authenticity and preservation. It has also been believed that reconstruction is the only way to prove one's financial condition and socio-economic status. The clan elders who advocate substantial reconstruction often have absolute influence in directing the entire execution of the conservation. In this manner, the appearance and forms rather than the authentic structures or objects are the target of preservation and only the traditional style will be kept. Such a trend shows the vulnerability of traditional architecture and historic objects preservation, as the reconstruction leaves the ancestral halls and houses with a traditional look only. The historical and cultural depth would be actually diminished.

\subsection{Diminished role of traditional craftsmen}

Craftsmen have a closed system of knowledge and skills, which are transferred from craftsmen to their apprentices through practices. They are commissioned by the property owners to plan, design, order materials and implement. The traditional construction industry is based on and ruled by their relationship with the property owners. However with the introduction of modern construction system, the traditional construction industry started to adopt the modern professional segregation of architectural design and construction. The traditional craftsmanship system are losing business in this new traditional architecture market and the craftsmen could only work as subcontractors for construction companies. As a result, projects are now directed by construction companies rather than master carpenters. The construction companies would have the wood and masonry systems designed, place custom orders with Chinese supplier and have the products shipped to Kinmen for assemblage and installation. The only work left for local craftsmen, no long in charge of the design and implementation, is to adjust or modify. Furthermore, due to the lower costs, construction companies would even hire craftsmen from the Chinese Mainland to work in place of local craftsmen through so-called three-month short-term exchange programme. Such practices do not only take job opportunities away from local traditional craftsmen, but also greatly affect their roles as craftsmen and the passing-on of their traditional skills.

\subsection{Impact of inadequate conservation resources}

There are some 3,000 traditional buildings in Kinmen today, and many people would like to continue living in their ancestral houses in traditional villages. There is thus a significant demand for conservation. Many traditional buildings were effectively conserved with the government conservation grants. The incentives contributed to the conservation of a large number of traditional buildings and created a trend of restoring houses and ancestral halls. With a limited annual budget for incentives, there is actually a conservation waiting list. 
Since the reconnection of construction network across the strait in 2001, due to geographic proximity, the Chinese Mainland has been the main provider of traditional building materials for Kinmen. However, despite the large demand for conservation, the materials used for conservation are not produced in a traditional way and the skills are not transferred. For example, as oyster shell ash production is banned due to the smoke emitted during the firing, the recipe of traditional ash mortar has to be altered. The oyster shell ash in the recipe is currently replaced with modern lime or a mixture of cement. However, after the conservation, a grey wall covered with this new generation of ash mortar cracks easily. In addition, with only a small number of craftsmen capable of making clay sculptures in Kinmen today, the property owners often had to use Chinesemade Koji pottery products instead. As to other craft skills, such as carpentry and coloured paining, the passing-on of the craftsmanship is endangered. Few young people would want to learn these skills as there is no incentives or any governmental counselling and protecting mechanism.

Until now, there is not yet a plan to properly promote scientific studies on conservation materials, passing-on of traditional skills and cultivation programmes for technical talents. As a result of massive demand and insufficient conservation resources combined, original objects and traditional appearance are often lost after conservation. One emerging issue is that more conservation work would actually do more damages to the heritage. Restoring an architectural heritage building with inadequate materials or wrong techniques will make it impossible to restore the original cultural and historical characteristics. Indeed, the cultural values and traditional construction industry are even more vulnerable in absence of proper counselling and craftsmanship preservation solution.

\section{Conclusion}

Since ancient times, Kinmen has been influenced by its neighbouring homeland. In a closed environment, it has slowly developed its own specific characteristics. Unfortunately, in the current architectural conservation rush, the original structures and materials that have been preserved for hundreds of years are replaced with new, fancy and fast-made products. Although the results satisfy people's pursuit of newness and change, the tangible heritage assets are impaired in the process. The close exchanges across the strait driven by a positively developed bilateral relationship and the interference of the fast and commercialised Chinese construction industry have caused a qualitative change in Kinmen's traditional craftsmen system. After conservation, the form of traditional architecture was changed due to such interaction. The change in architectural thinking underlines the vulnerable nature of traditional architecture conservation and the passing-on of the skills involved.

Currently, traditional architectural conservation focuses mainly on preserving the style and appearance of the building, rather than the architectural heritage or traditional culture. For local residents, despite the use of new structures or popular materials like modern face bricks, as long as their living space still look similar to the form and layout of traditional house, their empathy to the 
tradition will be fulfilled. A study into the ancestral hall and house conservation trend in Kinmen in recent years shows that the local residents do not think the architectural conservation is basically the preservation of the original objects that have survived the time and witnessed history. In the Venice Charter, restoration is clearly defined in the following statement: "The process of restoration is a highly specialized operation. Its aim is to preserve and reveal the aesthetic and historic value of the monument and is based on respect for original material and authentic documents." The strict requirements may not be applicable to most of the traditional buildings in Kinmen that are not registered as cultural heritage. Nevertheless, the result of the traditional architectural conservation practices in Kinmen in the past two decades indicates a qualitative change in Kinmen's architectural heritage. The change was caused by the consumer market operation and the recent trends of conservation dominated by the construction industries across the strait. Inaccurate understanding and inappropriate trend not only jeopardise the buildings with valuable cultural characteristics, but also decrease the opportunity for the traditional craftsmanship to be passed on during the current restructure of the construction industries across the strait. Under such impacts, the recovery of a vulnerable system is impossible.

Therefore, our common goals should include to reshape the traditional architectural culture through proper protection mechanism in the way that the passing-on of craft skills will no longer be threatened by the impact of modern construction industry; to improve the cultural resilience; to ensure the preservation based on authenticity values; and to promote appropriate conservation and restoration ideas.

\section{References}

[1] Ministry of National Defense, The 1958 Quemoy Crisis: An Oral History, Ministry of National Defense: Taipei, 2009.

[2] Szonyi, M., Cold War Island: Quemoy on the Front Line, Cambridge University Press: Cambridge, 2008.

[3] Tseng, Y. J., Chen, I. C., \& Huang, H. Y., Architectural Heritage Conservation under the Influence of Dominant Culture - A Case Study of the Island of Kinmen. Proc. of the "Heritage 2014" - 4th International Conference on Heritage and Sustainable Development, Green Lines Institute for Sustainable Development: Guimaraes, pp. 1149-1157, 2014.

[4] Cannon, T., Twigg, J. \& Rowell, J., Social vulnerability, sustainable livelihoods and disasters. Report to DFID, Conflict and Humanitarian Assistance Department (CHAD) and Sustainable Livelihoods Support Office: London, 2003, available at http://ipcc-wg2.gov/njlite download.php?id $=6377$

[5] Turner, B. L., et al., A Framework for Vulnerability Analysis in Sustainability Science. Proc. of the National Academy of Sciences of the United States of America, 100 (14), pp. 8074-8079, 2003.

[6] Adger, N.W., Nick, B., \& Bentham, G., New Indicators of Vulnerability and Adaptive Capacity, Technical Report 7, Tyndall Centre for Climate Change Research, 2004. 